\title{
Investigating circulating tumor cells and distant metastases in patient-derived orthotopic xenograft models of triple- negative breast cancer
}

Vishnu C. Ramani ${ }^{1}$, Clementine A. Lemaire ${ }^{2}$, Melanie Triboulet ${ }^{1}$, Kerriann M. Casey ${ }^{3}$, Kyra Heirich ${ }^{1}$, Corinne Renier ${ }^{2}$, José G. Vilches-Moure ${ }^{3}$, Rakhi Gupta ${ }^{1}$, Aryana M. Razmara ${ }^{3}$, Haiyu Zhang ${ }^{1}$, George W. Sledge ${ }^{4}$, Elodie Sollier ${ }^{2^{*}}$ (D) and Stefanie S. Jeffrey ${ }^{1 *}$

\begin{abstract}
Background: Circulating tumor cells (CTCS) represent a temporal "snapshot" of a patient's cancer and changes that occur during disease evolution. There is an extensive literature studying CTCs in breast cancer patients, and particularly in those with metastatic disease. In parallel, there is an increasing use of patient-derived models in preclinical investigations of human cancers. Yet studies are still limited demonstrating CTC shedding and metastasis formation in patient-derived models of breast cancer.

Methods: We used seven patient-derived orthotopic xenograft (PDOX) models generated from triple-negative breast cancer (TNBC) patients to study CTCS and distant metastases. Tumor fragments from PDOX tissue from each of the seven models were implanted into 57 NOD scid gamma (NSG) mice, and tumor growth and volume were monitored. Human CTC capture from mouse blood was first optimized on the marker-agnostic Vortex CTC isolation platform, and whole blood was processed from 37 PDOX tumor-bearing mice.
\end{abstract}

Results: Staining and imaging revealed the presence of CTCs in 32/37 (86\%). The total number of CTCs varied between different PDOX tumor models and between individual mice bearing the same PDOX tumors. CTCs were heterogeneous and showed cytokeratin (CK) positive, vimentin (VIM) positive, and mixed CKVIM phenotypes. Metastases were detected in the lung (20/57,35\%), liver $(7 / 57,12 \%)$, and brain (1/57, less than $2 \%)$. The seven different PDOX tumor models displayed varying degrees of metastatic potential, including one TNBC PDOX tumor model that failed to generate any detectable metastases ( $0 / 8$ mice) despite having CTCs present in the blood of 5/ 5 tested, suggesting that CTCS from this particular PDOX tumor model may typify metastatic inefficiency.

Conclusion: PDOX tumor models that shed CTCs and develop distant metastases represent an important tool for investigating TNBC.

Keywords: Circulating tumor cells (CTCS), Epithelial-mesenchymal transition (EMT), Liquid biopsy, NOD scid gamma (NSG), Patient-derived orthotopic xenograft (PDOX), Triple-negative breast cancer (TNBC)

\footnotetext{
* Correspondence: elodie@vortexbiosciences.com; ssj@stanford.edu

${ }^{2}$ Vortex Biosciences Inc., Pleasanton, CA, USA

'Department of Surgery, Stanford University School of Medicine, Stanford,

CA, USA

Full list of author information is available at the end of the article
}

(C) The Author(s). 2019 Open Access This article is distributed under the terms of the Creative Commons Attribution 4.0 International License (http://creativecommons.org/licenses/by/4.0/), which permits unrestricted use, distribution, and reproduction in any medium, provided you give appropriate credit to the original author(s) and the source, provide a link to the Creative Commons license, and indicate if changes were made. The Creative Commons Public Domain Dedication waiver (http://creativecommons.org/publicdomain/zero/1.0/) applies to the data made available in this article, unless otherwise stated. 


\section{Background}

Despite the tremendous progress made in the diagnosis and treatment of breast cancer, tumors of the breast still remain one of the leading causes of cancer-related deaths in women [1]. The intertumoral and intratumoral molecular heterogeneity of breast cancer challenges its diagnosis and effective treatment [2-9]. Tailored therapies, such as hormone therapies (e.g., tamoxifen and inhibitors of the enzyme aromatase, involved in estrogen synthesis) for ER-positive disease and trastuzumab (Her$\operatorname{ceptin}^{\odot}$ ) for HER2-overexpressing breast cancer have led to considerable success in treating some subtypes of breast cancer. However, drug resistance to these regimens can represent a major hurdle to successful treatment [10-15]. Most importantly, there is still no good targeted therapy for triple-negative breast cancer (TNBC), a very aggressive subtype that remains difficult to treat $[16,17]$. Due to the very aggressive nature of TNBC and the lack of well-established molecular therapeutic targets, patients with TNBC tend to have a relatively poorer outcome compared to patients with other subtypes [18, 19]. In breast cancer, and especially in TNBC, dissemination and metastatic growth of tumors at distant sites is the major cause of patient mortality [20]. Despite chemotherapy, fewer than 30\% of women diagnosed with metastatic TNBC will survive beyond 3 years, and, unfortunately, almost all women with metastatic TNBC will ultimately succumb to their metastatic disease [21-23]. Although newer therapies and combinations of therapies for TNBC are under active investigation and hold future promise, including the use of poly (ADP-ribose) polymerase (PARP) inhibitors for TNBC patients with homologous recombination DNA repairdeficient cancers associated with BRCA1 mutations, the use of immune checkpoint inhibitors, approaches that target other signaling pathways, or combination therapies, responses are still only observed in a small fraction of patients with advanced TNBC [24-30].

Factors that drive tumor metastasis have been a subject of intense scrutiny and research. As circulating tumor cells (CTCs) are considered contributory precursors that seed metastases in many cancers, including breast cancer, studying the biology of CTCs has provided vital clues regarding cancer metastasis [31]. Multiple mouse models may be used to study breast cancer biology, including syngeneic models (immunocompetent models generated from murine breast cancer cell lines, such as 4T1 cells), environmentally induced tumor models, transgenic models (models expressing mouse oncogenes, such as the polyomavirus middle $\mathrm{T}$ antigen controlled by the mouse mammary tumor virus long terminal repeat promoter, MMTV-PyMT model), genetically engineered mouse models (GEMMs), cell line-derived xenografts, and patient-derived xenografts
[32-39]. However, the use of in vivo models to study the shedding and biology of human CTCs requires either human breast cancer cell line-derived xenografts [40] or patient-derived xenografts (PDXs). Generation of PDX models involves the transplantation of primary human cancer cells or pieces of tumor tissue into immunocompromised mice. Although most PDX models are generated in mice lacking a functional human immune system, they are still considered to be highly clinically relevant $[41,42]$, particularly when implanted orthotopically (e.g., human breast tumor tissue from the operating room implanted into the mammary fat pads of mice). Orthotopically implanted PDX models, called patientderived orthotopic xenograft (PDOX) models, have been shown to recapitulate critical histological, genomic, transcriptomic, and proteomic features of the patients' tumors from which they were derived [43-45]; they are also better models of human metastatic disease [46] and of response to anti-cancer therapies [41, 45, 47] and, in the case of TNBC PDOX models, represent more aggressive phenotypes [48]. Currently, there is renewed interest in utilizing PDX models as evident in US National Cancer Institute's (NCI) plan to replace their NCI-60 cell line resource with PDX samples [49]. However, the background strain of mouse used for PDX studies is of key importance. NOD scid gamma (NSG) mice have been shown to be best at recapitulating the entire metastatic process in breast cancer from implantation in the mammary fat pad to distant metastatic spread, including development of metastases in cell line models that had not been previously associated with metastatic spread [50]. So while there has been an increasing interest in using PDOX models of breast cancer to study human CTCs captured from mouse blood and/ or human disseminated tumor cells (DTCs) from mouse bone marrow [51-57], the studies from these other groups were performed in non-NSG mouse models. We had previously described the isolation of CTCs from two NSG mice from a single TNBC PDOX tumor [58]. In this study, we use NSG mice to examine the distribution of distant metastatic spread in 57 mice from seven PDOX models of TNBC and to analyze CTC shedding in 37 of these mice.

Multiple technologies have been developed to enable CTC isolation from the peripheral blood of human patients with solid tumors. Approaches to capture and/or identify these rare cells rely on positive or negative cell selection, density gradient centrifugation, microfiltration, microfluidic or electrophoretic separation, direct imaging, or functional assays [59-61]. Here, we isolate human CTCs from mouse blood in PDOX models using the Vortex platform, a technology originally developed to allow fast and label-free isolation of human CTCs over a broad range of blood volumes $(200 \mu \mathrm{L}$ to $16 \mathrm{~mL})$. 
CTCs are enriched from whole blood based on size and deformability, using inertial microfluidics combined with microscale vortices [62]. This technique had been successfully used to isolate human CTCs from blood samples from patients with metastatic breast, lung, colorectal, and prostate cancer [63-67]. In the present study, isolation of human CTCs from mouse blood was first optimized using a human breast cancer cell linederived xenograft model of TNBC, generated from MDA-MB-231 cells, that we had previously shown to shed CTCs and metastasize to the lung [40]. Based on these experiments, a set of seven PDOX models of TNBC, including four that had previously undergone global genomic and transcriptomic analyses [44], were used for replicate isolation and characterization of human CTCs and for identification of sites of distant metastases.

\section{Methods}

\section{Vortex microfluidic chip design and operation}

Vortex chips are 70- $\mu$ m-deep microfluidic chips comprising a parallelized array of 16 straight channels, $40 \mu \mathrm{m}$ wide, with each channel leading to a series of 12 (Vortex HT chips) or 9 (Vortex VTX-1 chips) rectangular trapping reservoirs $(480 \mu \mathrm{m} \times 720 \mu \mathrm{m})$. Vortex HT PDMS chips were fabricated following conventional poly (dimethylsiloxane) (PDMS) fabrication processes with a 1:10 PDMS mix [68]. Vortex VTX-1 chips were fabricated with poly (methyl methacrylate) (PMMA) (Vortex Biosciences) using a standard lithography process [58]. The blood samples were injected through the chip as previously described [58]. Briefly, two syringe pumps (Harvard Apparatus) were connected to the chip using a plastic manifold, connectors (Upchurch), and tubing (Tefzel $^{\circ}$ (ETFE) Tubing Natural 1/16" OD × .040" ID from IDEX). One syringe was used for the blood sample and one syringe for the phosphate-buffered saline (PBS) wash buffer. After a priming step to fill the microfluidic path, the diluted blood sample was injected at $8 \mathrm{~mL} / \mathrm{min}$ to enable the CTC enrichment. A washing step with PBS was then injected at a similar flow rate to remove contaminating blood cells. Stopping the flow finally released the CTCs from the vortices to their collection downstream in a well plate.

\section{Cancer cell line culture and harvesting}

Cell lines used for characterization were grown aseptically to $30-60 \%$ confluence at $37^{\circ} \mathrm{C}$ in a humidified atmosphere of $5 \% \mathrm{CO}_{2}$. MDA-MB-231 (triple-negative breast carcinoma, $\left.\mathrm{ATCC}^{\circ} \mathrm{HTB}-26^{\mathrm{m}}\right)$ cells were grown in DMEM medium supplemented with $10 \%$ inactivated FBS and 1\% penicillin/streptomycin. Adherent cells were dissociated with TrypLE express cell dissociation reagent (Gibco) and resuspended in complete media. For experiments related to Fig. 2, the cell line used was MDA-MB-231 cells that stably expressed firefly luciferase-enhanced green fluorescent protein (FLuceGFP), a generous gift from the Paulmurugan lab at Stanford University [69].

\section{Cell immunostaining and enumeration}

After Vortex processing of mice blood, cells were collected in a cell culture-treated 96-well plate (Nunc), fixed for $10 \mathrm{~min}$ with an equal volume of $4 \%$ paraformaldehyde (PFA; Electron Microscopy Sciences) for a final concentration of $2 \%$ PFA, permeabilized for 7 min with 0.4\% Triton X-100 (Sigma Aldrich) volume/volume for a final concentration of $0.2 \%$, blocked for 30 min with $10 \%$ goat serum (Invitrogen), and then stained for $1 \mathrm{~h}$ at room temperature (RT). The immunostains were 4,6diamidino-2-phenylindole (DAPI) (Life Technologies), a rat anti-mouse CD45-PE antibody (CD45-PE, clone 30F11, BD Pharmingen), and a cocktail of primary antibodies labeled with fluorescein isothiocyanate (FITC) to identify cytokeratin (CK)-positive cells (human anticytokeratin clone CK3-6H5, Miltenyi Biotec, and human anti-cytokeratin clone CAM5.2, BD Biosciences) [58]. For patient-derived orthotopic xenograft (PDOX) samples and MDA-MB-231 tumor xenograft samples, an anti-CK-AlexaFluor (AF) 488 antibody (human anti-pan cytokeratin clone AE1/AE3, eBioscience) and an antivimentin-AF647 antibody (clone V9, Abcam, reactive to human vimentin; non-reactive to mouse vimentin) were used in addition to the previously listed antibodies (Additional file 1: Figure S1). After staining, the cells were imaged using an Axio Observer Z1 microscope (Zeiss) and manually enumerated as described previously $[58,68]$. Stitched images of stained cells were acquired, and cells enumerated by two different persons following a classification criterion developed at Vortex $[58,66,68]$. The cells were categorized into three large groups, namely CTCs (CK+/CD45-/DAPI+, VIM+/ CD45-/DAPI+, and CK+/VIM+/CD45-/DAPI+), WBCs (CK-/CD45+/DAPI+, VIM-/CD45+/DAPI+, and VIM+/CD45+/DAPI+), or debris.

\section{CTC isolation from mouse blood \\ Cell spiking in healthy mouse blood}

Two hundred to 500 MDA-MB-231 cells prepared as described above were spiked into $500 \mu \mathrm{L}$ of blood isolated from healthy $\mathrm{BALB} / \mathrm{c}$ mice via cardiac puncture and collected into EDTA-coated microtainer tubes. The spiked blood was diluted $10 \times, 20 \times$, or $40 x$ in filtered PBS and processed using the Vortex VTX-1 plastic chip. Once captured, the cells were released into a well plate, stained and enumerated. Capture performance can be described by cancer cell recovery and capture contamination using the following equations: 


$$
\begin{aligned}
& \text { Cell recovery }(\%)=\frac{\text { \#of target cells captured }}{\text { \#of target cells spiked into the sample }} \\
& \text { Capture contamination }(\mathrm{WBCs} / \mathrm{mL})=\frac{\text { \#of WBCs captured }}{\text { volume of blood processed }}
\end{aligned}
$$

\section{PDOX samples}

At time of euthanasia and necropsy, blood $(\sim 750 \mu \mathrm{L})$ was collected via cardiac puncture from PDOX-bearing mice and diluted 40x with filtered PBS. The diluted samples were processed through Vortex VTX-1 plastic chips, and the isolated CTCs were immunostained and enumerated as described above.

\section{Animal studies}

All studies were approved by the Stanford University Research Compliance Office's Human Subjects Research and IRB Panel and Stanford's Administrative Panel on Laboratory Animal Care (APLAC). All methods were performed in accordance with the relevant guidelines and regulations. All seven TNBC PDOX tumor models were generated from fresh-frozen live tumor tissue fragments from our bank of previously established patientderived orthotopoic xenograft tumor models, including four models of different TNBC subtypes that were previously characterized using global genomic and transcriptomic analyses [44]. Tumor samples were collected from patients in accordance with the relevant IRB guidelines. Briefly, frozen fragments of tumor were thawed and washed once with RPMI-1640 media and transported under aseptic conditions to the Stanford animal facility. One to $2 \mathrm{~mm}$ fragments of individual PDOX tumors were then sterilely and orthotopically transplanted into the fourth mammary fat pads of at least 5 female NOD scid gamma (NSG) mice (NOD.Cg-Prkdc ${ }^{\text {scid }} I l 2 r g^{t m 1 W j l}$, SzJ (Jackson Laboratory West, Sacramento, CA, USA). These mice have deficiencies in innate immunity, and due to the severe combined immune deficiency mutation (scid) and an IL2 receptor gamma chain deficiency that disables cytokine signaling, they lack mature $\mathrm{T}$ cells, B cells, and functional NK cells and are deficient in cytokine signaling. In contrast to the more leaky NOD scid mice, NSG mice have a longer lifespan with more resistance to lymphoma.

Animals were anesthetized using 1 to $3 \%$ isoflurane, hair at the implantation site was removed, and skin was sterilized with povidone-iodine and alcohol. A small skin incision was made, and the fourth mammary fat pad was identified. The fat pad was gently held with forceps while a small nick was made to create a pocket where tumor fragments were then placed. The skin incision was closed using interrupted monofilament sutures. Mice were maintained in pathogen-free animal housing. For MDA-MB-231 xenograft studies, a mixture of cell suspension and Matrigel (LDEV-free, Growth Factor Reduced, BD Biosciences) was injected into the fourth mammary fat pad. All the animals were monitored regularly, and tumor growth was measured at regular intervals. Tumor volume was calculated by the following formula: tumor volume $=\left(l \times w^{2}\right) / 2$, where $l$ was the longest diameter of the tumor and $w$ was the shortest diameter of the tumor. Mean tumor volumes were calculated, and growth curves were established as a function of time. All animal care was performed in accordance with IACUC and Stanford University Administrative Panels on Laboratory Animal Care guidelines (APLAC Protocol \#12809).

For testing the impact of route of blood collection on CTC numbers, the TNBC xenograft models used were generated from MDA-MB-231 human breast cancer cells that stably expressed firefly luciferase-enhanced green fluorescent protein (FLuc-eGFP), as mentioned above, with tumor cells and CTCs showing green fluorescence. Briefly, $8 \times 10^{6}$ MDA-MB-231-FLuc-eGFP cells were injected orthotopically into the fourth mammary fat pads of NSG mice $(n=35)$. Tumor volumes were measured three times per week for all the animals. Starting from week 1 post injection, blood via cardiac puncture $(500 \mu \mathrm{L})(n=3$ animals $)$ or via lateral saphenous vein $(100 \mu \mathrm{L})(n=3$ animals) was collected weekly, diluted to $40 \times$, and processed on the Vortex platform to enrich for CTCs. After staining, CTCs were enumerated. For testing the retroorbital route of blood collection, blood from non-tumor-bearing NSG control mice was collected, processed on the Vortex platform, and stained for DAPI, cytokeratin, and CD45.

\section{H\&E analyses for metastases}

Upon termination of the experiment, animals bearing PDOX tumors were humanely euthanized via $\mathrm{CO}_{2}$ asphyxiation. Blood, tumor tissue, and organs were collected immediately following euthanasia. Lungs from individual animals were inflated with $10 \%$ neutral buffered formalin (NBF) prior to submersion and storage in $10 \%$ NBF. All organs were immersion-fixed in $10 \%$ NBF for at least $48 \mathrm{~h}$ prior to transferring to $70 \%$ ethanol. Fixed sections of the lung, liver, and brain were routinely processed and embedded in paraffin, then serially sectioned at $5 \mu \mathrm{m}$ and stained with hematoxylin and eosin (H\&E; HISTO-TEC laboratories, Hayward, CA). Five serial H\&E sections of each individual organ were then screened for tumor metastases at $\times 4$ and $\times 40$ magnification (Zeiss Axioskop 2 Plus) by board-certified veterinary pathologists (KMC and JGMV). Photomicrographs of metastases were captured and visualized using a Nikon DS-Ri1 camera and NIS-Elements Imaging Software (2011), respectively. 


\section{Results}

Optimization of CTC isolation from mouse blood samples with spiking experiments

\section{Effect of blood dilution}

Mouse blood is less viscous than human blood [70] but of significantly smaller total volume, usually less than 2 $\mathrm{mL}$ per animal. Small volumes of collected blood pose a challenge for processing through fluidic tubing and microfluidic components because of the risk of loss of rare target cells in dead volume. To overcome this issue, diluting the blood sample becomes essential. In a previous study, different dilutions of human blood were tested on the Vortex technology, and the results demonstrated that a $10 \times$ dilution was optimal for cancer cell recovery and throughput [62]. To establish a dilution strategy for mouse blood, 200 MDA-MB-231 human breast cancer cells were spiked into $500 \mu \mathrm{L}$ of healthy mouse blood, diluted with PBS $(40 \times, 20 \times$, and $10 \times)$ and processed on the Vortex platform (Fig. 1a). As illustrated in Fig. 1b, a similar cancer cell recovery was obtained for $40 \times$ and $20 \times$ dilutions (46.55\% and $44.34 \%$ recovery) and 74 and 52 WBCs were also captured. With the $10 \times$ dilution, the recovery was poor $(17.89 \%)$. Based on these results, a 40x dilution of mouse blood was used for all ensuing experiments.

\section{Effect of recycling the blood efflux}

To optimize CTC recovery from a small blood volume, we devised a strategy of recycling, wherein after processing once (first cycle), the efflux is collected and reinjected into the microfluidic chip for a second and third time (second and third cycles), to capture additional cancer cells that might have escaped capture in the first round of processing (Fig. 1c). For testing the efficiency of recycling, 500 MDA-MB-231 cells were spiked into $500 \mu \mathrm{L}$ of mouse blood and processed through the microfluidic chip for up to three cycles. When processed in the High Purity Mode (one cycle), 34.38\% of cells were collected on average. Cycling a sample twice captured $44.73 \%$ of the cancer cells. When the same sample was processed in the High Recovery Mode (three cycles), $47.96 \%$ of the cells were recovered. However, recycling also increased the number of co-isolated WBCs $(447$ WBCs with three cycles combined, compared to 171 with one cycle). For the following experiments, two cycles were selected as optimal.

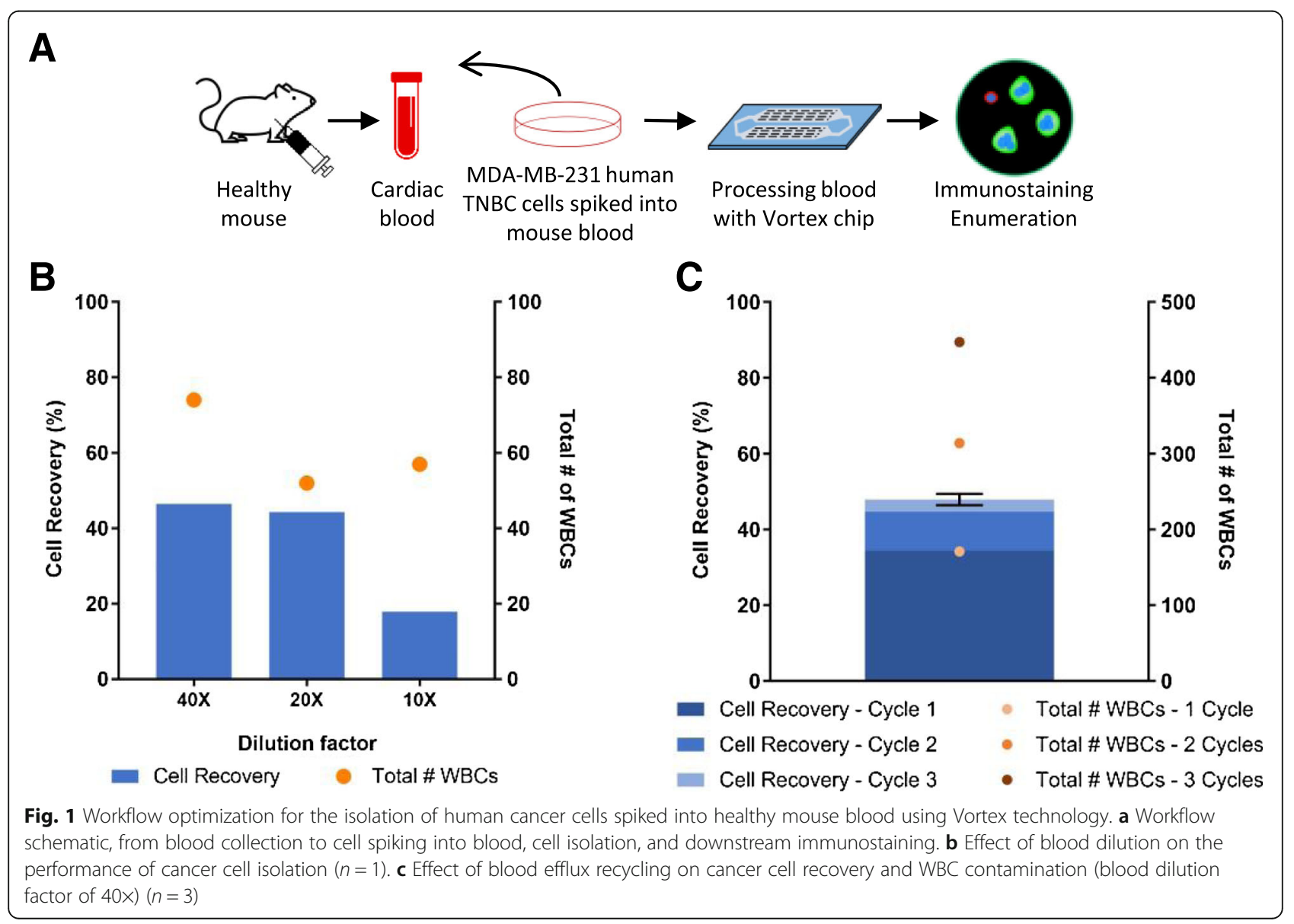




\section{Effect of blood collection site on CTC capture}

Blood samples from mice bearing MDA-MB-231 tumor xenografts were collected at different time intervals from the saphenous vein or by cardiac puncture as tumor size increased (Fig. 2). CTCs were detected in blood collected via cardiac puncture as early as day 7. CTC counts ranged from 0.4 to $3649 \mathrm{CTCs} / 100 \mu \mathrm{L}$ and increased over time, correlating with tumor burden (Fig. 2b). CTC clusters were also captured from day 7 (6 clusters $/ 100 \mu \mathrm{L}$; frequency $1 / 3$ ), with number and frequency increasing over time up to $147-485$ clusters $/ 100 \mu \mathrm{L}$ by day 42 (Fig. 2c). In contrast, no CTCs were recovered from blood obtained from the lateral saphenous vein until day 28 postimplantation, and their number remained low (mean $2.15 \pm 0.65 \mathrm{CTCs} / 100 \mu \mathrm{L}$ ) (Fig. 2d). Blood collected from the retroorbital sinus from healthy control animals without tumors had high numbers of contaminating epithelial (CK+/DAPI+/CD45-) cells making this route of blood collection unsuitable for CTC studies (Fig. 2e).

\section{Characterization of tumor growth, metastases, and CTCs in PDOX models of triple-negative breast cancer}

After implantation of fragments of TNBC PDOX tumor tissue into NSG mice, individual tumor volume was calculated and plotted as a function of time; after sacrifice, organs were examined and, in a subset of mice, blood was processed for CTCs (Fig. 3a). Different PDOX tumor models grew at different rates, and there were differences in tumor growth rates in individual mice bearing the same PDOX tumors (Fig. 3b).

To test for metastatic spread in our TNBC PDOX models, the lung, liver, and brain were screened for metastases by serial section and hematoxylin and eosin (H\&E) staining (Fig. 3c). Metastases were detected in the lung $(20 / 57,35 \%)$, liver $(7 / 57,12 \%)$, and brain $(1 / 57$, $2 \%$ ), with different TNBC PDOX models displaying varying sites and frequencies of metastases (Table 1). For example, PDOX tumor model SUTI151 displayed a high frequency of metastases with two thirds of the animals bearing this tumor showing metastases in at least one organ. Interestingly, this TNBC PDOX model was the most aggressive, derived from a patient's rapidly metastasizing breast cancer that was refractory to all standard therapies; the SUTI151 model also exhibited the highest number of CTCs per tumor-bearing mouse compared to other PDOX models in this study. We detected a brain metastasis in only one PDOX tumor model, SUBRTU2 (Fig. 3c and Table 1). Notably, one PDOX model in our cohort, SUTI368, showed no metastases at necropsy.

Histologically, metastases were noted in association with vascular structures of the lung and liver (Fig. 3c). Within the lung, neoplastic thromboemboli were found in medium- to small-caliber pulmonary vessels (Fig. 3c, $\times 20$ magnification), as well as within capillaries of the alveolar septa (Fig. 3c, $\times 40$ magnification). Within medium- to small-caliber vessels, neoplastic thromboemboli partially to completely occluded vascular lumina and were segmentally adherent to the vascular endothelium. Occasionally, there was disruption of the vascular wall, and associated luminal and extraluminal fibrin deposition (Fig. 3c, black triangle). Within the lungs, neoplastic aggregates were occasionally associated with concentric bands of fibrous connective tissue (desmoplasia, Fig. 3c, white arrow). Within the liver, discrete neoplastic aggregates were randomly distributed within the sinusoids of the hepatic parenchyma. Concomitant desmoplasia was not noted within any of the examined sections of the liver. Neoplastic cells were polygonal with distinct cell borders and a low to moderate amount of eosinophilic cytoplasm. Nuclei were round to ovoid with finely stippled chromatin and up to one discrete nucleolus. Variation in cell size (anisocytosis) and nuclear size (anisokaryosis) were moderate, and mitotic figures were frequent (Fig. 3c, black arrows). Occasional bizarre mitotic figures were noted. Rarely, individual cell necrosis was characterized by contracted hypereosinophilic cytoplasm and karyorrhectic to pyknotic nuclei.

\section{CTCs in TNBC PDOX models}

To test for the presence of CTCs in our seven different TNBC PDOX models, we processed whole blood isolated via cardiac puncture from 37 of the PDOX tumorbearing mice using the Vortex CTC isolation platform (Fig. 3a). Staining and imaging of captured cells revealed the presence of CTCs in all seven PDOX models tested, even in the SUTI368 model that showed no distant metastases (Fig. 4, Table 1). The total number of CTCs varied between different PDOX tumor models and between individual mice bearing the same PDOX tumor model (Table 1).

\section{Isolation of CTC clusters}

We found that both our MDA-MB-231 cell line-derived and PDOX models revealed the presence of CTC clusters (Fig. 2c and Fig. 5), and only one of our PDOX models, SUTI151, revealed the presence of CTC clusters. Importantly, some of the captured CTC clusters from this model displayed a clear heterogeneity in cytokeratin and vimentin staining among the individual cells present within the cluster.

\section{CTCs from TNBC PDOX models showed markers of epithelial, mesenchymal, and mixed phenotypes}

CTCs detected in our different PDOX tumor models of TNBC expressed basic epithelial $(\mathrm{CK}+)$ and/or mesenchymal (VIM+) markers, suggesting that individual CTCs may be in the process of undergoing epithelialmesenchymal transition (EMT) (Figs. 4 and 6). 


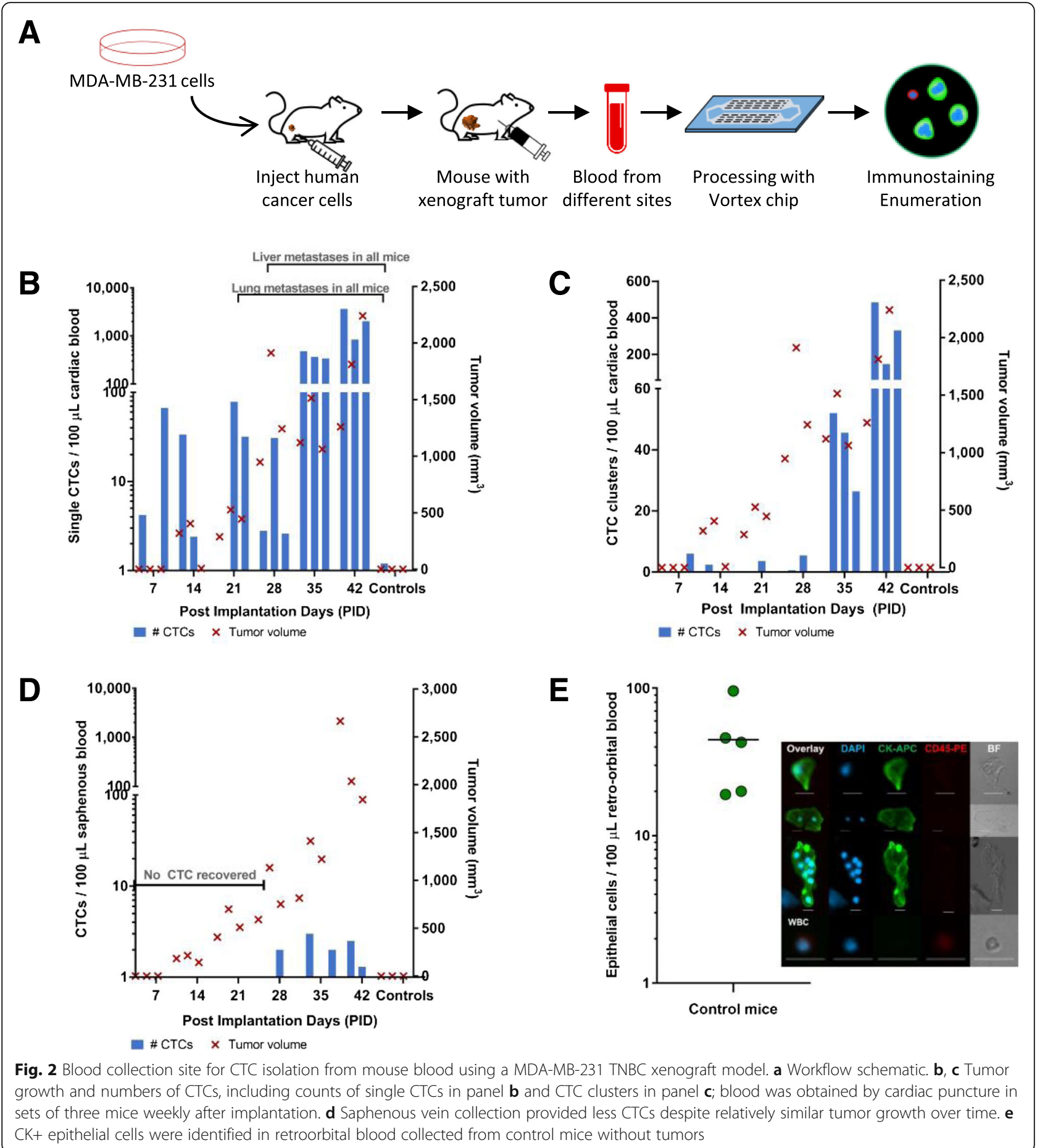

Quantifying CTCs isolated from the TNBC PDOX model SUTI151 demonstrated that while some CTCs showed an epithelial phenotype (cytokeratin-positive, vimentin-negative) or a mesenchymal phenotype (cytokeratin-negative, vimentin-positive), the great majority of CTCs from this model expressed a mixed phenotype, positive for both cytokeratin and vimentin (Fig. 6a).
Grouping the CTCs into distinct subsets based on the expression of these markers from two individual mice bearing SUTI151 tumors (as mentioned above, this model was derived from a particularly aggressive TNBC that metastasized rapidly) showed that the percentage of CTCs in each subset between the two animals were fairly similar (Fig. 6b). While such results highlight the 
A

B
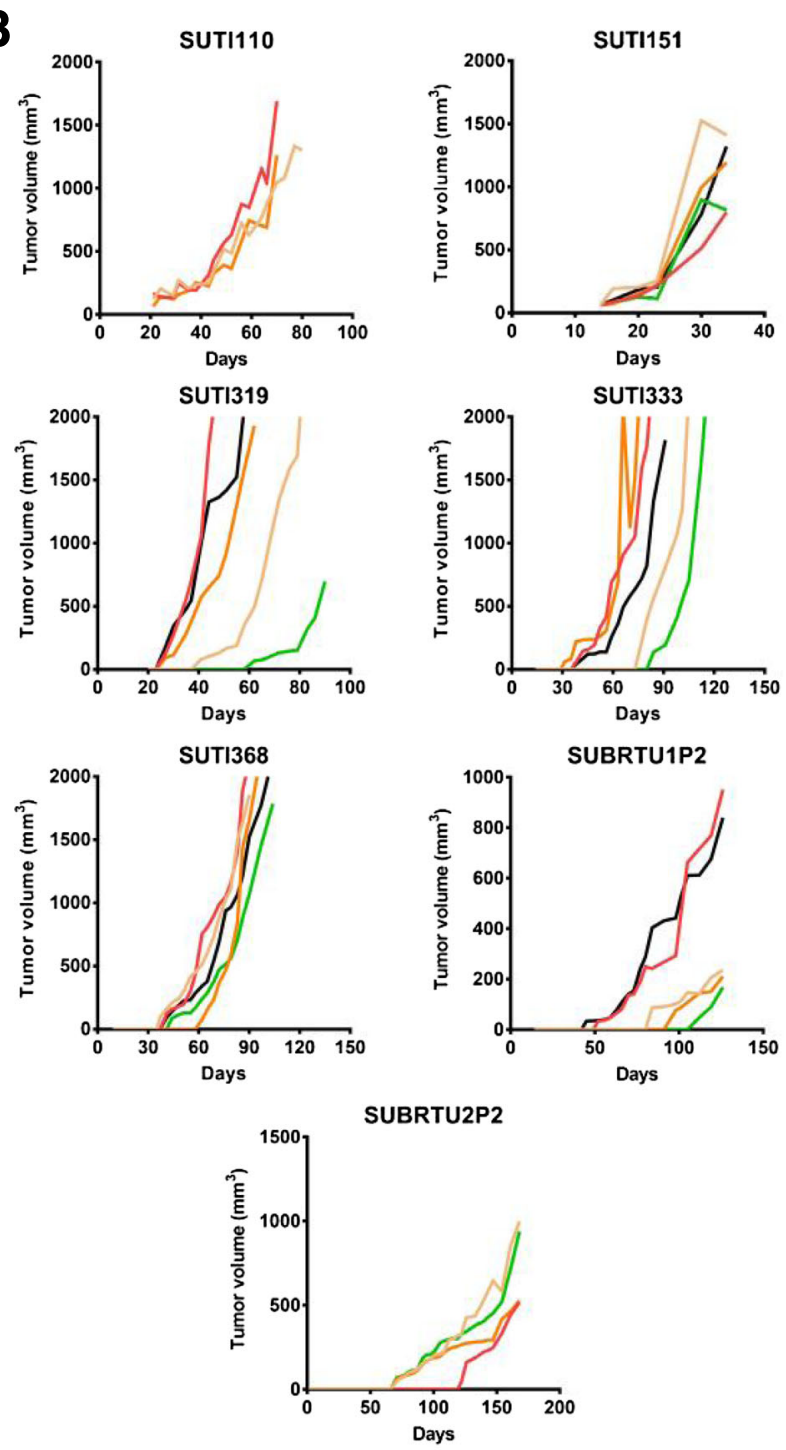

\section{$\boldsymbol{\gamma}_{\text {Tumor volume }}^{\text {त }}$}

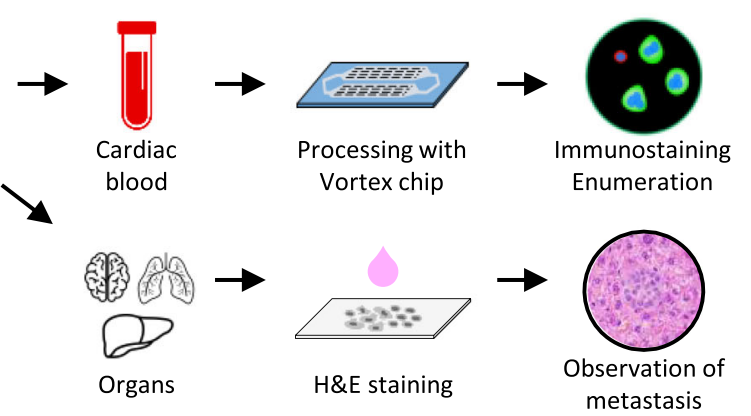

C

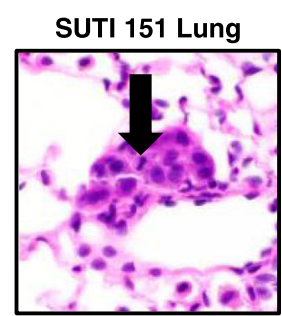

SUTI 151 Liver
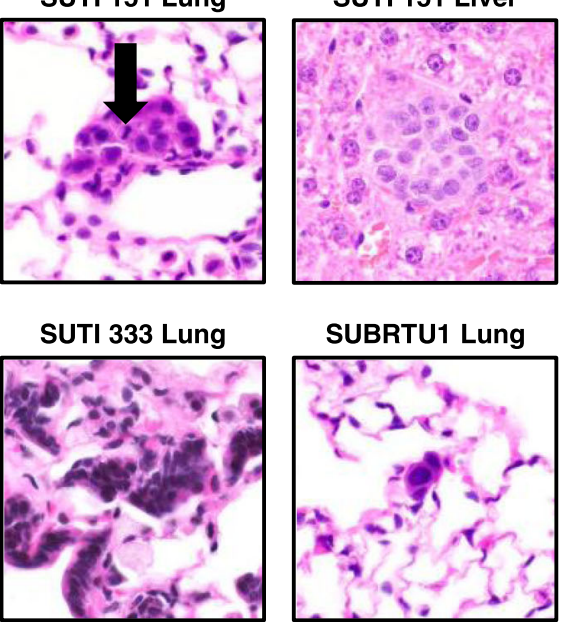

SUBRTU1 Lung
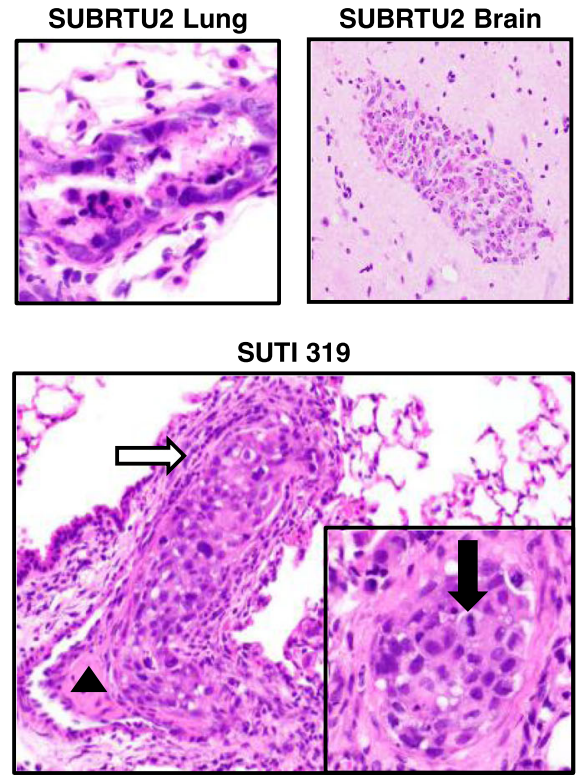

Fig. 3 (See legend on next page.) 
(See figure on previous page.)

Fig. 3 Growth rate and metastases in PDOX models of TNBC. a For individual animals, tumor fragments from previously derived and passaged PDOX tumors were implanted orthotopically in the fourth mammary fat pad and tumor volume was measured over time; at the end of the experiment, cardiac blood was collected for CTC isolation, and multiple organs were analyzed for metastases. b Representative growth curves for seven different PDOX tumor models grown in NSG mice. c Metastases were identified in the lung, liver, and rarely, brain of mice bearing the human TNBC tumors (H\&E, $\times 20$ and $\times 40$ magnifications). Pulmonary metastases were found within alveolar septal capillaries or medium- to small-caliber vessels, where they were associated with peri-tumoral fibrin (black triangle) and/or desmoplasia (white arrow). Hepatic metastases were randomly distributed within hepatic sinusoids. Mitotic figures (black arrows) were frequently identified within metastatic foci

utility of PDOX models for further investigations of EMT in CTCs, a strong correlation of EMT and the ability of CTCs to generate metastases would require further thorough investigation involving multiple PDOX models that display EMT changes. Here, it was only seen in one of our seven TNBC PDOX models.

\section{Discussion}

Circulating tumor cells, detected most often in metastatic cancer [71], are a key player in the metastatic cascade [31]. We have recently reported on label-free isolation and analysis of CTCs from two PDOX tumorbearing mice as part of an evaluation of Vortex' fully automated VTX-1 Liquid Biopsy System [58]. Here, we investigated CTC shedding and metastases in TNBC PDOX models, examining 57 mice from a cohort of seven TNBC PDOX models for distant metastases in serially sectioned lung, liver, and brain, and using a marker-agnostic CTC isolation platform to isolate and analyze CTCs from 37 of these mice.

As far as we are aware, seven previous studies have used breast cancer PDOX models to capture and analyze CTCs from mouse blood or DTCs from mouse bone marrow. One study [54] used a previous TP53 wildtype PDOX model of non-basal TNBC to generate cell lines that were transduced with lentivirus encoding CBR-luc and mCherry (FUW-CBR-luc-mCherry) and then infected with control retroviruses or retroviruses encoding p53-specific short hairpin RNAs (shRNAs) to knock down $\mathrm{p} 53$. They then implanted these wildtype and p53deficient transduced cells into cleared mammary fat pads of NOD/SCID mice whose stroma was humanized using immortalized and irradiated human mammary stromal fibroblasts derived from a patient undergoing a reduction mammoplasty. Tumor growth; metastases to the lung, bone, liver, brain, and axillary lymph node; and CTC shedding (quantified using flow cytometry) were compared between wildtype and p53-deficient tumors. Although their PDOX models were generated very differently than ours, similar to our findings, metastatic tumor was identified at different sites in differing fractions of mice. Moreover, although CTC shedding increased with time, a finding more pronounced in mice whose tumors were p53-deficient, with numbers of CTCs in the less than 15 range at 9 weeks to the less than 220 range at 18 weeks, CTC shedding appeared more related to total primary and metastatic tumor burden. A different study [55] used PDOX models derived from five tumors of different breast cancer molecular subtypes that were implanted in humanized mammary fat pads (previously cleared and injected with GFPlabeled immortalized human fibroblasts) of NOD/SCID mice to investigate DTCs and distant metastases. Here, mouse bone marrow was analyzed by performing qRT-

Table 1 Tabulated results of metastases detected in 57 mice bearing seven different TNBC PDOX tumor models. Thirty-seven blood samples obtained by cardiac puncture from these seven TNBC tumor models were processed for CTC isolation

\begin{tabular}{|c|c|c|c|c|c|c|c|c|c|c|}
\hline PDOX & $\begin{array}{l}\text { Tumor } \\
\text { Subtype }\end{array}$ & $\begin{array}{l}\text { Metastases } \\
\text { Detected }\end{array}$ & $\begin{array}{l}\text { \# of Mice } \\
\text { with } \\
\text { Metastases } \\
\text { (\%) }\end{array}$ & $\begin{array}{l}\text { Sites with } \\
\text { Metastases }\end{array}$ & $\begin{array}{c}\text { CTCs } \\
\text { Detected }\end{array}$ & $\begin{array}{l}\text { \# of } \\
\text { Samples } \\
\text { Processed }\end{array}$ & $\begin{array}{c}\text { \# of } \\
\text { Samples } \\
\text { with CTCs } \\
(\%)\end{array}$ & $\begin{array}{l}\text { CTCs/ml } \\
\text { (min-max) }\end{array}$ & $\begin{array}{l}\text { Median } \\
\text { CTCs } / \mathrm{ml}\end{array}$ & $\begin{array}{l}\text { Approx. } \\
\text { Time } \\
\text { to Reach } \\
1000 \mathrm{~mm}^{3}\end{array}$ \\
\hline SUTI110 & TNBC & Yes & 1/3 (33.3) & Lung only $(n=1)$ & Yes & 2 & $2 / 2(100)$ & $9-40$ & 24.7 & 10 weeks \\
\hline SUTI151 & TNBC & Yes & $10 / 15(66.7)$ & $\begin{array}{l}\text { Lung \& Liver }(n=3) \\
\text { Lung only }(n=4) \\
\text { Liver only }(n=3)\end{array}$ & Yes & 12 & $11 / 12$ (91.7) & $0-2006$ & 13.3 & 5-7 weeks \\
\hline SUT1319 & TNBC & Yes & $7 / 9(77.8)$ & $\begin{array}{l}\text { Lung \& Liver }(n=1) \\
\text { Lung only }(n=6)\end{array}$ & Yes & 5 & $4 / 5(80)$ & $0-51$ & 38.7 & 7 weeks \\
\hline SUTI333 & TNBC & Yes & $1 / 8(12.5)$ & Lung only $(n=1)$ & Yes & 6 & $3 / 6(50)$ & $0-33$ & 2.0 & 10 weeks \\
\hline SUT1368 & TNBC & No & $0 / 8(0)$ & None & Yes & 5 & $5 / 5(100)$ & $4-14$ & 5.3 & 10 weeks \\
\hline SUBRTU1 & TNBC & Yes & $1 / 8(12.5)$ & Lung only $(n=1)$ & Yes & 5 & $5 / 5(100)$ & $24-45$ & 34.3 & 18 weeks \\
\hline SUBRTU2 & TNBC & Yes & $3 / 6(50)$ & $\begin{array}{l}\text { Lung \& Brain }(\mathrm{n}=1) \\
\text { Lung only }(\mathrm{n}=2)\end{array}$ & Yes & 2 & $2 / 2(100)$ & $4-6$ & 5.3 & 24 weeks \\
\hline
\end{tabular}




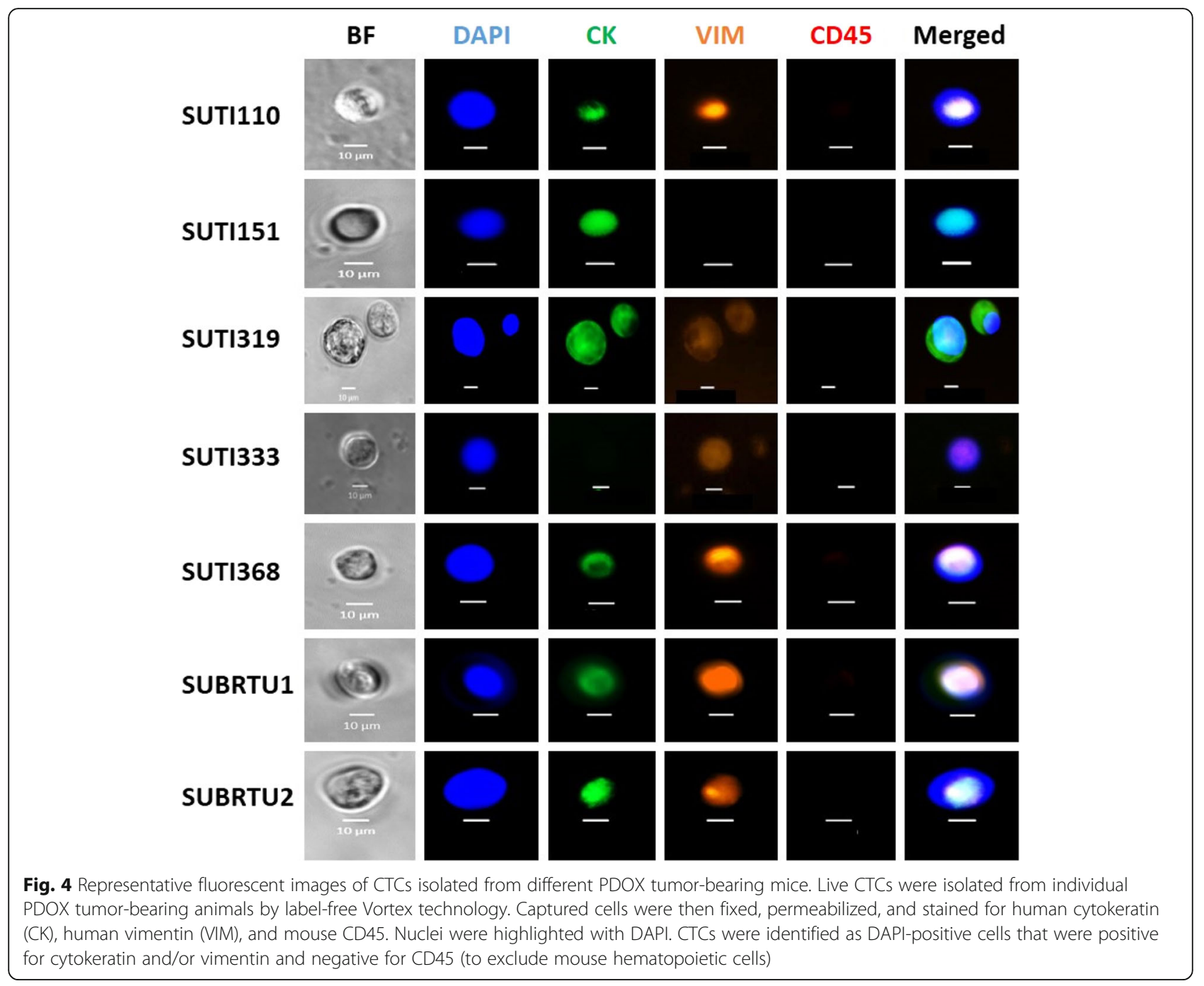

PCR for human transcripts as well as microarray analysis of gene expression in primary tumors, the bone marrow, and a metastatic lesion in one mouse. Only two PDOX tumor models developed metastases, both of which had human DTCs and which had variable sites of metastases. Global gene expression between diverse sources in the one mouse tested, a TNBC PDOX model, was also variable, but seemed to show patterns of human gene expression "reminiscent of a 'mesenchymal-like' phenotype in multiple animals across multiple passages," with the authors suggesting that DTCs from the bone marrow may have undergone a phenotypic transition that enabled migration to and survival in the bone marrow, similar to many of the CTCs we observed in our current study. Another study [52] measured CTCs from blood and DTCs from the bone marrow, detected using antihuman pan-cytokeratin immunohistochemistry (IHC), in 18 different breast cancer PDOX models, 13 of which were TNBC PDOX models, generated from human breast tumors implanted into the cleared mammary fat pads of SCID/beige mice. Again, differing fractions of individual mice in each model had detectable CTCs (overall, present in $83 \%$ of PDOX models) and/or DTCs (overall, present in 63\% of PDOX models) and lung metastases (overall, present in 50\% of PDOX models). Although no specific mesenchymal-like IHC marker was used, there was still a strong association between CTC and DTC detection. Importantly, all mice with lung metastases had detectable CTCs but not all mice with detectable CTCs had lung metastases, similar to our findings. A strong association between CTC clusters and the presence of lung metastases was also found. In a fourth study [51], single-cell suspensions of seven patient-derived breast tumors were orthotopically injected into SCID mice; two PDOX tumors developed CTCs as detected by an EpCAM-based platform, and no metastases were observed in any of the seven mice. An important study by the Werb group [53] using three PDOX models of TNBC in NOD/SCID mice showed that all models shed CTCs into blood, with variable 


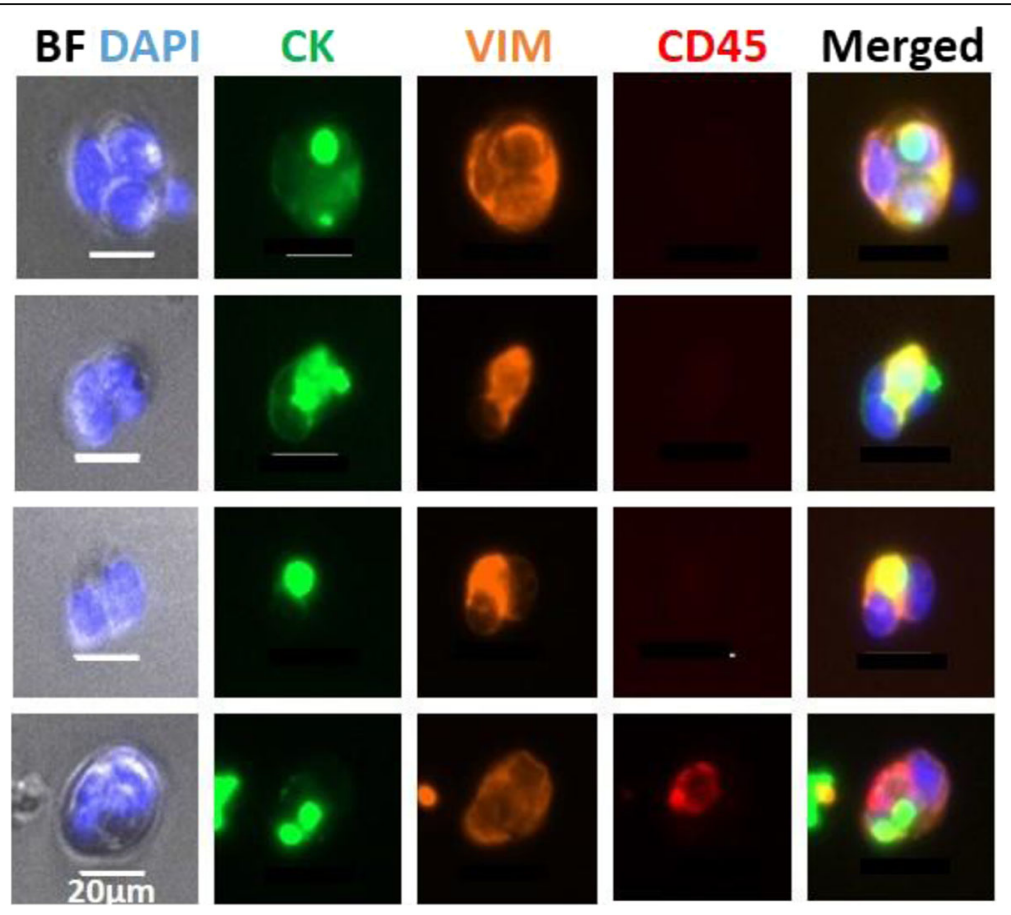

Fig. 5 CTC clusters from mice bearing MDA-MB-231 xenograft tumors. CTC clusters were isolated using the Vortex platform and stained with DAPI, human cytokeratin (CK), human vimentin (VIM), and mouse CD45. CTCs within clusters were identified as cells positive for DAPI, cytokeratin, and/or vimentin and negative for CD45. Note the heterogeneous composition of cells within some clusters

CTC shedding $(7 / 31$ mice $=23 \%$ in one TNBC model had detectable cancer cells in their peripheral blood; $1 /$ 19 mice $=5 \%$ in another TNBC model had detectable cancer cells in their peripheral blood; and $3 / 22$ mice $=$ $14 \%$ in a third TNBC model had detectable cancer cells in their peripheral blood). All models developed metastases in different organs, but again, like our study, showed variability among individual mice within a TNBC model. Excitingly, single-cell gene expression signatures of cells from tissues with low and high

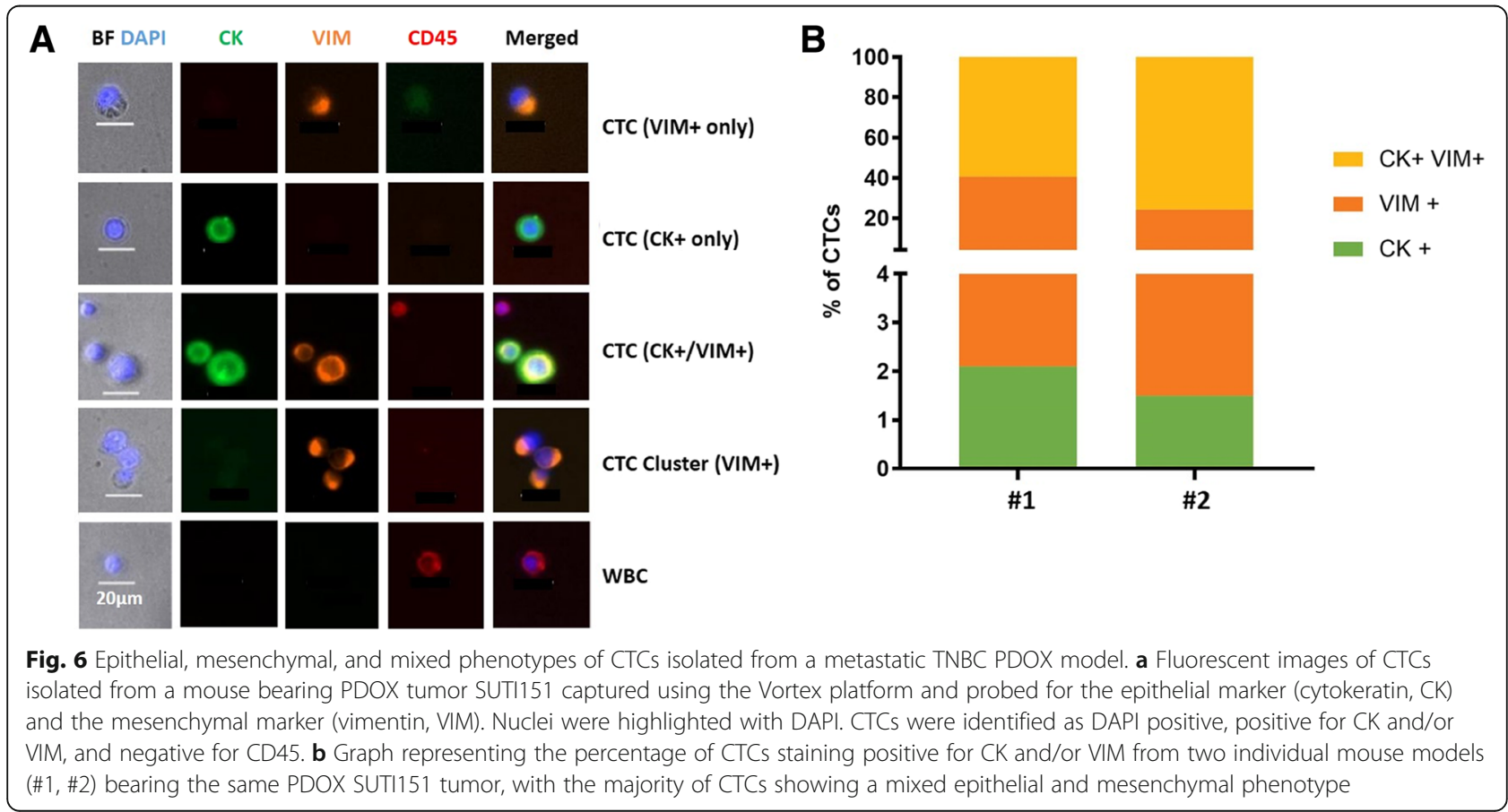


metastatic burden and CTCs showed that a subpopulation of stem-like CTCs may potentially represent "metastatic seeder cells." A recent study of CTCs in non-NSG mice [56] used the same PDOX models described in their previous work $[45,52]$ but with CTCs isolated using a different CTC isolation platform that improved on CTC number and allowed identification of the PIK3CA T1035A mutation in single cells from CTCs, primary tumors, and lung metastases in one of their PDOX models. Finally, an interesting new study that analyzed human RNA transcripts in the blood (positive for CTCs), bone marrow (positive for DTCs), and tumor in severe combined immunodeficient (SCID) xenograft mouse models found that CTCs from an ER-positive PDOX model of lobular carcinoma expressed a possibly uncoupled epithelial-mesenchymal plasticity and lower expression of stem cell-like markers than CTCs from a cell line-derived TNBC xenograft [57].

A challenge when studying in vivo CTC models has been identifying an appropriate route of blood collection for maximal CTC yield for downstream analyses. We addressed this question first by using a metastatic, human TNBC cell line, MDA-MB-231, and discovered that blood collected via cardiac puncture yielded higher numbers of CTCs and CTC clusters, with some clusters heterotypic and containing both CTCs and WBCs. The importance of blood collection route for CTC analyses in mouse xenograft models was nicely addressed using cell line-derived xenografts and an EpCAM-based CTC isolation platform [51], concluding that cardiac puncture was the best route for obtaining CTCs compared to tail vein, retroorbital, and jugular vein aspiration. Similar to our findings, blood samples from the retroorbital venous plexus were uniformly contaminated by CTC-like normal murine epithelial cells in control mice without tumors. They also found that jugular vein aspiration yielded CTCs in only $15 \%$ of samples and also showed normal murine epithelial cell contamination from jugular vein aspiration in control mice. To our knowledge, our results are the first to address blood collection route using a marker-agnostic CTC isolation platform. While the cardiac route of blood collection is superior in its CTC yield, a major limitation of this route is that, as used here, it is a terminal method of blood collection, thereby limiting its application for serial CTC monitoring.

Analyzing CTCs and distant metastases in different breast cancer PDOX models also depends on the genetic background of the mouse model selected. A recent study highlighted challenges and limitations of metastatic TNBC PDOX models using SCID mice [72]. The authors discussed several challenges that included low rate of metastases, long periods for metastases in the lungs to be detected, and development of thymic lymphomas of mouse origin, using their SCID mouse models. SCID mice may also develop spontaneous non-thymic tumors, including mammary adenocarcinomas [73]. Pertinently, while younger NSG models do not develop spontaneous tumors, a recent study of aging female NSG mice showed that tumors may indeed develop in mice of median age 52 weeks, when age was available, including $31 \%$ developing spontaneous mammary gland neoplasms [74], a recent finding for which the PDOX community should be made aware.

In another study using $\mathrm{NCr}$ nude and SCID mice, only 2/7 PDOX models yielded CTCs and none had detectable distant metastases [51]. Addressing the issue of mouse model background, the Lippman group showed that NSG mice are superior for generating distant metastases in cell line- and patient-derived orthotopic xenograft models [50]. Using NSG mice for our study, most PDOX tumors grew aggressively and produced large tumors within 3 months of implantation, with detectable metastatic lesions in $6 / 7$ of our TNBC PDOX tumor models.

In our study, the percentage of PDOX tumor-bearing mice with metastases ranged from $78 \%$ for SUTI319 to 0 for SUTI368. It is interesting to note that although CTCs were detected in 5/5 of SUTI368 tumor-bearing mice, no distant metastases were detected in eight SUTI368 PDOX mice. While serial sectioning of organs was sufficient to detect metastases in the majority of our PDOX models, we may have missed micrometastases in un-sectioned portions of an organ that perhaps a more sensitive PCR-based approach, based on detecting human DNA in mouse whole organs, could have potentially detected, including PDOX model SUTI368 [75]. However, a more likely explanation for the presence of CTCs in 5/5 mice and lack of metastases in $0 / 8$ mice from this model is that metastasis is an inefficient process [76]. In a classic murine melanoma model with intravital video-microscopy, metastatic inefficiency was found to be mainly due to (1) lack of initiation of growth (i.e., dormancy) of solitary cancer cells in a distant organ and (2) lack of growth of initial micrometastases into macroscopic tumors and vulnerability to early destruction [77]. This has also been confirmed in multiple other tumor models, including breast cancer [78], and additional mechanisms have been proposed as to why only a subset of circulating tumor cells may be associated with the development of metastases [79-81].

While the SUTI368 model is capable of generating CTCs, the tumor cells in circulation may not be capable of establishing metastatic growth because they may lack the ability to initiate the critical tumor-host interactions or may not possess intrinsic biomechanical or other molecular properties necessary for establishing metastases [82-85]. Moreover, it is interesting to note that even 
when all the individual animals were implanted with tumor tissue fragments from the same PDOX tumor, there were differences in tumor growth rates between the individual tumor-bearing animals as well as differences in the development of and site of metastases within the same PDOX tumor model. Heterogeneity in the amount of tumor tissue and associated stromal tissue in each fragment implanted, differences in the number of viable tumor cells, and the molecular heterogeneity of tumor cells in individual tumor fragments could trigger such different growth rates in vivo. To overcome such discrepancies, we are also using single-cell suspensions of tumor tissue for generating and passaging more uniform PDOX tumors (data not shown).

CTCs can exist as single cells or clusters, and CTC clusters are predicted to have a greater potential to establish metastases than individual CTCs [86-90]. In mouse models of breast cancer, CTC clusters appear to be derived from oligoclonal groupings of primary tumor cells and have been shown to be a highly metastasiscompetent subset of CTCs, compared to single circulating breast cancer cells [86, 87]. CTC clusters also may provide additional prognostic value in human breast cancer [91-93], and in patients with breast, prostate, and small cell lung cancer, the presence of single or increasing numbers of CTC clusters in sampled blood is found to correlate significantly with reduced progressionfree survival rates $[86,91-96]$. As a result, there has been an interest in isolating and understanding CTC clusters in different cancers and, in addition to filter and other technologies that identify clusters, some CTC isolation technologies have been specifically designed for isolating CTC clusters [97-99] or exploring their behavior [100]. In our studies, using the Vortex CTC isolation platform, we demonstrate rapid and efficient isolation of CTCs and CTC clusters from both cell line-derived xenograft and PDOX models of breast cancer. As this platform is markeragnostic, we were able to capture heterogeneous clusters of CTCs that included individual cells that varied in the expression of CTC markers tested, demonstrating its utility for examining the biology and heterogeneity of CTC clusters in different cancer models.

Another notable finding in our current study is the difference in the heterogeneous distribution of cytokeratin (epithelial), vimentin (mesenchymal), and mixed cytokeratin and vimentin markers in CTCs and CTC clusters within and between the TNBC PDOX tumors. For example, while some CTCs from these PDOX tumor models showed high expression of the epithelial marker cytokeratin or the mesenchymal marker vimentin, many CTCs stained strongly for both cytokeratin and vimentin. The distribution of epithelial-like, mesenchymal-like, and mixed epithelial and mesenchymal CTC phenotypes represents an important aspect of CTC heterogeneity.
CTC heterogeneity, including differences in gene expression of vimentin and five other EMT markers, was previously highlighted by our group using high-dimensional single-cell transcriptional profiling of human CTCs from breast cancer patients, where cell-to-cell heterogeneity of CTCs was noted even within the same blood draw [101]. This was also demonstrated through the work of other groups that has shown mixtures of epithelial- and mesenchymal-like CTCs in human blood samples of breast and other cancers [102-104]. It has been postulated that hybrid EMT phenotypes may promote the development of cancer metastases [105-107], although how the role of EMT plasticity and the different EMT states precisely contribute to the metastatic process still remains under active investigation [108-114]. Heterogeneity among CTCs and resulting metastases may also be attributed to (i) differences in methylation patterns of specific genes [115], (ii) selective and differential expression of particular genes in a subset of CTCs [101, 116119], and/or (iii) expression of certain genes at different stages of the disease [120-123].

\section{Conclusion}

Our data describes the heterogeneous distribution of lung, liver, and brain metastases in a group of seven TNBC PDOX models and confirms the shedding of CTCs captured by a marker-agnostic CTC isolation platform. It supports further use of PDOX models, generated in NSG mice, to study PDOX-derived CTCs, distant metastases, and for testing the impact and outcome of different anti-cancer agents on CTC shedding and metastasis in breast cancer.

\section{Additional file}

Additional file 1: Figure S1. As a staining specificity control, human tumor cells from the MDA-MB-231 human TNBC cell line and mouse tumor cells from the 4T1 mouse TNBC cell line were both stained with the same set of antibodies used in the current study. The anti-pan cytokeratin antibody cocktail and the anti-vimentin antibody strongly stained human tumor cells; 4T1 mouse tumor cells showed minimal or absent staining with the same set of antibodies. (DOCX $234 \mathrm{~kb}$ )

\section{Acknowledgements}

The authors thank Prof. R. Paulmurugan at Stanford University for sharing his MDA-MB-231-FLuc-eGFP cell line.

\section{Authors' contributions}

VCR, CR, GWS, ES, and SSJ designed and planned the experiments. VCR, CAL, $M T, K H, R G$, and $H Z$ performed the experiments; KMC and JGVM performed histologic studies. VCR, CAL, KMC, CR, AMR, GWS, ES, and SSJ analyzed the data. VCR, CAL, KMC, GWS, ES, and SSJ wrote the manuscript with assistance from the other authors. All authors have reviewed and approved this manuscript.

\section{Funding}

This study was funded in part by Vortex Biosciences through a research contract with Stanford University (SSJ), the Susan G. Komen Foundation SAB1500003 (GWS, SSJ), the Breast Cancer Research Program of the 
Department of Defense W81XWH-14-1-0398 (SSJ), and the John and Marva Warnock Research Fund (SSJ).

\section{Availability of data and materials}

All data generated or analyzed during this study are included in this published article and can be shared by contacting the corresponding authors.

\section{Ethics approval and consent to participate}

All studies were approved by the Stanford University Research Compliance Office's Human Subjects Research and IRB Panel and Stanford's Administrative Panel on Laboratory Animal Care (APLAC). All methods were performed in accordance with the relevant guidelines and regulations. Patient tumor samples were collected from patients in accordance with the relevant IRB guidelines.

\section{Consent for publication}

Not applicable.

\section{Competing interests}

$C A L, C R$, and ES have financial interests in Vortex Biosciences and intellectual property described herein. The other authors declare that they have no competing interests.

\section{Author details}

${ }^{1}$ Department of Surgery, Stanford University School of Medicine, Stanford, CA, USA. ${ }^{2}$ Vortex Biosciences Inc., Pleasanton, CA, USA. ${ }^{3}$ Department of Comparative Medicine, Stanford University School of Medicine, Stanford, CA, USA. ${ }^{4}$ Department of Medicine, Stanford University School of Medicine, Stanford, CA, USA

\section{Received: 29 April 2019 Accepted: 5 August 2019}

\section{Published online: 28 August 2019}

\section{References}

1. Siegel RL, Miller KD, Jemal A. Cancer statistics, 2018. CA Cancer J Clin. 2018; 68:7-30.

2. Deng $\mathrm{G}$, et al. Single cell mutational analysis of PIK3CA in circulating tumor cells and metastases in breast cancer reveals heterogeneity, discordance, and mutation persistence in cultured disseminated tumor cells from bone marrow. BMC Cancer. 2014;14:456.

3. Zardavas D, Irrthum A, Swanton C, Piccart M. Clinical management of breast cancer heterogeneity. Nat Rev Clin Oncol. 2015;12:381-94.

4. Beca F, Polyak K. Intratumor heterogeneity in breast cancer. Adv Exp Med Biol. 2016:882:169-89.

5. Roulot A, et al. Tumoral heterogeneity of breast cancer. Ann Biol Clin (Paris). 2016;74:653-60.

6. Savas $P$, et al. The subclonal architecture of metastatic breast cancer: results from a prospective community-based rapid autopsy program "CASCADE". PLoS Med. 2016;13:e1002204.

7. Avigdor BE, et al. Mutational profiles of breast cancer metastases from a rapid autopsy series reveal multiple evolutionary trajectories. JCI Insight. 2017;2:24.

8. Ellsworth RE, Blackburn HL, Shriver CD, Soon-Shiong P, Ellsworth DL. Molecular heterogeneity in breast cancer: state of the science and implications for patient care. Semin Cell Dev Biol. 2017;64:65-72.

9. Turashvili G, Brogi E. Tumor heterogeneity in breast cancer. Front Med (Lausanne). 2017:4:227. https://doi.org/10.3389/fmed.2017.00227.

10. Osborne CK, Schiff R. Mechanisms of endocrine resistance in breast cancer Annu Rev Med. 2011;62:233-47.

11. De Marchi T, Foekens JA, Umar A, Martens JW. Endocrine therapy resistance in estrogen receptor (ER)-positive breast cancer. Drug Discov Today. 2016; 21:1181-8

12. Luque-Cabal M, García-Teijido P, Fernández-Pérez Y, Sánchez-Lorenzo L, Palacio-Vázquez I. Mechanisms behind the resistance to trastuzumab in HER2-amplified breast cancer and strategies to overcome it. Clin Med Insights Oncol. 2016:10(Suppl 1):21-30.

13. Gingras I, Gebhart G, de Azambuja E, Piccart-Gebhart M. HER2-positive breast cancer is lost in translation: time for patient-centered research. Nat Rev Clin Oncol. 2017;14:669-81.
14. Parakh S, et al. Evolution of anti-HER2 therapies for cancer treatment. Cancer Treat Rev. 2017;59:1-21.

15. Reinhardt F, Franken A, Fehm T, Neubauer H. Navigation through inter- and intratumoral heterogeneity of endocrine resistance mechanisms in breast cancer: a potential role for liquid biopsies? Tumour Biol. 2017;39: 1010428317731511

16. Kalimutho $\mathrm{M}$, et al. Targeted therapies for triple-negative breast cancer: combating a stubborn disease. Trends Pharmacol Sci. 2015;36:822-46.

17. Székely B, Silber AL, Pusztai L. New therapeutic strategies for triple-negative breast cancer. Oncology (Williston Park). 2017;31:130-7.

18. Malorni $L$, et al. Clinical and biologic features of triple-negative breast cancers in a large cohort of patients with long-term follow-up. Breast Cancer Res Treat. 2012:136:795-804

19. Bianchini G, Balko JM, Mayer IA, Sanders ME, Gianni L. Triple-negative breast cancer: challenges and opportunities of a heterogeneous disease. Nat Rev Clin Oncol. 2016;13:674-90

20. Redig AJ, McAllister SS. Breast cancer as a systemic disease: a view of metastasis. J Intern Med. 2013;274:113-26.

21. Bonotto $\mathrm{M}$, et al. Measures of outcome in metastatic breast cancer: insights from a real-world scenario. Oncologist. 2014;19:608-15

22. Zhang J, et al. Chemotherapy of metastatic triple negative breast cancer: experience of using platinum-based chemotherapy. Oncotarget. 2015;6: 43135-43.

23. Gobbini $\mathrm{E}$, et al. Time trends of overall survival among metastatic breast cancer patients in the real-life ESME cohort. Eur J Cancer. 2018;96:17-24.

24. Geenen JJJ, Linn SC, Beijnen JH, Schellens JHM. PARP inhibitors in the treatment of triple-negative breast cancer. Clin Pharmacokinet. 2018;57(4): 427-37.

25. Costa RLB, Han HS, Gradishar WJ. Targeting the PI3K/AKT/mTOR pathway in triple-negative breast cancer: a review. Breast Cancer Res Treat. 2018;169(3): 397-406.

26. Prasanna T, et al. Optimizing poly (ADP-ribose) polymerase inhibition through combined epigenetic and immunotherapy. Cancer Sci. 2018; 109(11):3383-92.

27. Soundararajan $\mathrm{R}$, et al. Targeting the interplay between epithelial-tomesenchymal-transition and the immune system for effective immunotherapy. Cancers (Basel). 2019;11:5.

28. Voorwerk $\mathrm{L}$, et al. Immune induction strategies in metastatic triple-negative breast cancer to enhance the sensitivity to PD-1 blockade: the TONIC trial. Nat Med. 2019:25(6):920-8.

29. Sceneay J, et al. Interferon signaling is diminished with age and is associated with immune checkpoint blockade efficacy in triple-negative breast cancer. Cancer Discov. 2019. https://doi.org/10.1158/2159-8290.CD-18-1454.

30. McCann KE, Hurvitz SA, McAndrew N. Advances in targeted therapies for triple-negative breast cancer. Drugs. 2019:79(11):1217-30.

31. Lambert AW, Pattabiraman DR, Weinberg RA. Emerging biological principles of metastasis. Cell. 2017:168:670-91.

32. Guy CT, Cardiff RD, Muller WJ. Induction of mammary tumors by expression of polyomavirus middle T oncogene: a transgenic mouse model for metastatic disease. Mol Cell Biol. 1992;12:954-61

33. Lin EY, et al. Progression to malignancy in the polyoma middle $\mathrm{T}$ oncoprotein mouse breast cancer model provides a reliable model for human diseases. Am J Pathol. 2003:163:2113-26.

34. Herschkowitz Jl, et al. Identification of conserved gene expression features between murine mammary carcinoma models and human breast tumors. Genome Biol. 2007;8:R76

35. Rashid OM, et al. An improved syngeneic orthotopic murine model of human breast cancer progression. Breast Cancer Res Treat. 2014;147:501-12.

36. Manning HC, Buck JR, Cook RS. Mouse models of breast cancer: platforms for discovering precision imaging diagnostics and future cancer medicine. J Nucl Med. 2016;57(Suppl 1):605-8S.

37. Puchalapalli $M$, et al. NSG mice provide a better spontaneous model of breast cancer metastasis than athymic (nude) mice. PLoS One. 2016;11: e0163521.

38. Gengenbacher N, Singhal M, Augustin HG. Preclinical mouse solid tumour models: status quo, challenges and perspectives. Nat Rev Cancer. 2017:17:751-65.

39. Kitz J, Lowes LE, Goodale D, Allan AL. Circulating tumor cell analysis in preclinical mouse models of metastasis. Diagnostics (Basel). 2018;8(2). https://doi.org/10.3390/diagnostics8020030.

40. Ameri $\mathrm{K}$, et al. Circulating tumour cells demonstrate an altered response to hypoxia and an aggressive phenotype. Br J Cancer. 2010;102:561-9. 
41. Izumchenko E, et al. Patient-derived xenografts effectively capture responses to oncology therapy in a heterogeneous cohort of patients with solid tumors. Ann Oncol. 2017;28:2595-605.

42. Sulaiman A, Wang L. Bridging the divide: preclinical research discrepancies between triple-negative breast cancer cell lines and patient tumors. Oncotarget. 2017:8:113269-81.

43. Petrillo LA, et al. Xenografts faithfully recapitulate breast cancer-specific gene expression patterns of parent primary breast tumors. Breast Cancer Res Treat. 2012;135:913-22.

44. Zhang $\mathrm{H}$, et al. Patient-derived xenografts of triple-negative breast cancer reproduce molecular features of patient tumors and respond to mTOR inhibition. Breast Cancer Res. 2014;16:R36.

45. Zhang $X$, et al. A renewable tissue resource of phenotypically stable, biologically and ethnically diverse, patient-derived human breast cancer xenograft models. Cancer Res. 2013;73:4885-97.

46. Hoffman RM. Patient-derived orthotopic xenografts: better mimic of metastasis than subcutaneous xenografts. Nat Rev Cancer. 2015;15:451-2.

47. Byrne AT, et al. Interrogating open issues in cancer precision medicine with patient-derived xenografts. Nat Rev Cancer. 2017;17:254-68.

48. Moon HG, et al. Prognostic and functional importance of the engraftmentassociated genes in the patient-derived xenograft models of triple-negative breast cancers. Breast Cancer Res Treat. 2015;154:13-22.

49. Ledford H. US cancer institute to overhaul tumour cell lines. Nature. 2016; 530:391.

50. lorns $E$, et al. A new mouse model for the study of human breast cancer metastasis. PLoS One. 2012;7:e47995.

51. Eliane JP, et al. Monitoring serial changes in circulating human breast cancer cells in murine xenograft models. Cancer Res. 2008;68:5529-32.

52. Giuliano $M$, et al. Circulating and disseminated tumor cells from breast cancer patient-derived xenograft-bearing mice as a novel model to study metastasis. Breast Cancer Res. 2015;17:3.

53. Lawson DA, et al. Single-cell analysis reveals a stem-cell program in human metastatic breast cancer cells. Nature. 2015;526:131-5.

54. Powell $E_{\text {, et al. }}$ 53 deficiency linked to $B$ cell translocation gene 2 (BTG2) loss enhances metastatic potential by promoting tumor growth in primary and metastatic sites in patient-derived xenograft (PDX) models of triplenegative breast cancer. Breast Cancer Res. 2016;18:13.

55. Pillai SG, et al. Identifying biomarkers of breast cancer micrometastatic disease in bone marrow using a patient-derived xenograft mouse model. Breast Cancer Res. 2018;20:2.

56. Ramirez $A B$, et al. Circulating tumor cell investigation in breast cancer patient-derived xenograft models by automated immunofluorescence staining, image acquisition, and single cell retrieval and analysis. BMC Cancer. 2019;19(1):220.

57. Tachtsidis A, et al. Human-specific RNA analysis shows uncoupled epithelialmesenchymal plasticity in circulating and disseminated tumour cells from human breast cancer xenografts. Clin Exp Metastasis. 2019;36(4):393-409.

58. Lemaire CA, et al. Fast and label-free isolation of circulating tumor cells from blood: from a research microfluidic platform to an automated fluidic instrument, VTX-1 Liquid Biopsy System. SLAS Technol. 2018. https://doi. org/10.1177/247263031773869.

59. Ignatiadis M, Lee M, Jeffrey SS. Circulating tumor cells and circulating tumor DNA: challenges and opportunities on the path to clinical utility. Clin Cancer Res. 2015;21:4786-800.

60. Ferreira MM, Ramani VC, Jeffrey SS. Circulating tumor cell technologies. Mol Oncol. 2016;10:374-94

61. Gabriel MT, Calleja LR, Chalopin A, Ory B, Heymann D. Circulating tumor cells: a review of non-EpCAM-based approaches for cell enrichment and isolation. Clin Chem. 2016;62:571-81.

62. Sollier $\mathrm{E}$, et al. Size-selective collection of circulating tumor cells using Vortex technology. Lab Chip. 2014;14:63-77.

63. Dhar M, et al. Label-free enumeration, collection and downstream cytological and cytogenetic analysis of circulating tumor cells. Sci Rep. 2016;6:35474.

64. Kidess-Sigal $E$, et al. Enumeration and targeted analysis of KRAS, BRAF and PIK3CA mutations in CTCS captured by a label-free platform: comparison to ctDNA and tissue in metastatic colorectal cancer. Oncotarget. 2016;7:85349-64.

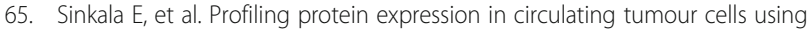
microfluidic western blotting. Nat Commun. 2017;8:14622.

66. Renier $\mathrm{C}$, et al. Label-free isolation of prostate circulating tumor cells using Vortex microfluidic technology. NPJ Precis Oncol. 2017;1:15.
67. Liu HE, et al. Workflow optimization of whole genome amplification and targeted panel sequencing for CTC mutation detection. NPJ Genom Med. 2017;2:34.

68. Che J, et al. Classification of large circulating tumor cells isolated with ultrahigh throughput microfluidic Vortex technology. Oncotarget. 2016;7:12748-60.

69. Paulmurugan $\mathrm{R}$, et al. Folate receptor-targeted polymeric micellar nanocarriers for delivery of orlistat as a repurposed drug against triplenegative breast cancer. Mol Cancer Ther. 2016;15:221-31.

70. Windberger U, Bartholovitsch A, Plasenzotti R, Korak KJ, Heinze G. Whole blood viscosity, plasma viscosity and erythrocyte aggregation in nine mammalian species: reference values and comparison of data. Exp Physiol. 2003;88:431-40.

71. Cabel L, et al. Circulating tumor cells: clinical validity and utility. Int J Clin Oncol. 2017;22:421-30.

72. Paez-Ribes M, Man S, Xu P, Kerbel RS. Development of patient derived xenograft models of overt spontaneous breast cancer metastasis: a cautionary note. PLoS One. 2016;11:e0158034.

73. Huang P, Westmoreland SV, Jain RK, Fukumura D. Spontaneous nonthymic tumors in SCID mice. Comp Med. 2011;61:227-34

74. Santagostino SF, Arbona RJR, Nashat MA, White JR, Monette S. Pathology of aging in NOD scid gamma female mice. Vet Pathol. 2017;54:855-69.

75. Preston Campbell J, et al. TRIzol and Alu qPCR-based quantification of metastatic seeding within the skeleton. Sci Rep. 2015;5:12635.

76. Weiss L. Metastatic inefficiency. Adv Cancer Res. 1990;54:159-211.

77. Luzzi KJ, et al. Multistep nature of metastatic inefficiency: dormancy of solitary cells after successful extravasation and limited survival of early micrometastases. Am J Pathol. 1998;153:865-73.

78. Chambers AF, Naumov GN, Vantyghem SA, Tuck AB. Molecular biology of breast cancer metastasis. Clinical implications of experimental studies on metastatic inefficiency. Breast Cancer Res. 2000;2:400-7.

79. Azevedo AS, Follain G, Patthabhiraman S, Harlepp S, Goetz JG. Metastasis of circulating tumor cells: favorable soil or suitable biomechanics, or both? Cell Adhes Migr. 2015;9:345-56

80. Massagué J, Obenauf AC. Metastatic colonization by circulating tumour cells. Nature. 2016;529:298-306.

81. Strilic B, Offermanns S. Intravascular survival and extravasation of tumor cells. Cancer Cell. 2017;32:282-93.

82. Labelle M, Hynes RO. The initial hours of metastasis: the importance of cooperative host-tumor cell interactions during hematogenous dissemination. Cancer Discov. 2012;2:1091-9.

83. Labelle M, Begum S, Hynes RO. Platelets guide the formation of early metastatic niches. Proc Natl Acad Sci U S A. 2014;111:E3053-61.

84. Rejniak KA. Circulating tumor cells: when a solid tumor meets a fluid microenvironment. Adv Exp Med Biol. 2016;936:93-106.

85. Dasgupta A, Lim AR, Ghajar CM. Circulating and disseminated tumor cells: harbingers or initiators of metastasis? Mol Oncol. 2017;11:40-61.

86. Aceto N, et al. Circulating tumor cell clusters are oligoclonal precursors of breast cancer metastasis. Cell. 2014;158:1110-22.

87. Cheung KJ, et al. Polyclonal breast cancer metastases arise from collective dissemination of keratin 14-expressing tumor cell clusters. Proc Natl Acad Sci U S A. 2016;113:E854-63.

88. Cheung KJ, Ewald AJ. A collective route to metastasis: seeding by tumor cell clusters. Science. 2016:352:167-9.

89. Suo $Y$, et al. Proportion of circulating tumor cell clusters increases during cancer metastasis. Cytometry A. 2017:91:250-3.

90. Giuliano M, et al. Perspective on circulating tumor cell clusters: why it takes a village to metastasize. Cancer Res. 2018;78:845-52.

91. Mu Z, et al. Prospective assessment of the prognostic value of circulating tumor cells and their clusters in patients with advanced-stage breast cancer. Breast Cancer Res Treat. 2015;154:563-71.

92. Wang C, et al. Longitudinally collected CTCs and CTC-clusters and clinical outcomes of metastatic breast cancer. Breast Cancer Res Treat. 2017;161:83-94.

93. Larsson AM, et al. Longitudinal enumeration and cluster evaluation of circulating tumor cells improve prognostication for patients with newly diagnosed metastatic breast cancer in a prospective observational trial. Breast Cancer Res. 2018:20:48.

94. Hou JM, et al. Clinical significance and molecular characteristics of circulating tumor cells and circulating tumor microemboli in patients with small-cell lung cancer. J Clin Oncol. 2012;30:525-32.

95. Hong Y, Fang F, Zhang Q. Circulating tumor cell clusters: what we know and what we expect (review). Int J Oncol. 2016;49:2206-16.

96. Fabisiewicz A, Grzybowska E. CTC clusters in cancer progression and metastasis. Med Oncol. 2017;34:12. 
97. Sarioglu AF, et al. A microfluidic device for label-free, physical capture of circulating tumor cell clusters. Nat Methods. 2015;12:685-91.

98. Au SH, et al. Microfluidic isolation of circulating tumor cell clusters by size and asymmetry. Sci Rep. 2017;7:2433.

99. Cheng SB, et al. Three-dimensional scaffold chip with thermosensitive coating for capture and reversible release of individual and cluster of circulating tumor cells. Anal Chem. 2017;89:7924-32.

100. Au SH, et al. Clusters of circulating tumor cells traverse capillary-sized vessels. Proc Natl Acad Sci U S A. 2016;113:4947-52.

101. Powell $A A$, et al. Single cell profiling of circulating tumor cells: transcriptional heterogeneity and diversity from breast cancer cell lines. PLoS One. 2012;7:e33788.

102. Kallergi $\mathrm{G}$, et al. Epithelial to mesenchymal transition markers expressed in circulating tumour cells of early and metastatic breast cancer patients. Breast Cancer Res. 2011:13:R59.

103. Yu M, et al. Circulating breast tumor cells exhibit dynamic changes in epithelial and mesenchymal composition. Science. 2013:339:580-4.

104. Alix-Panabières C, Mader S, Pantel K. Epithelial-mesenchymal plasticity in circulating tumor cells. J Mol Med (Berl). 2017;95:133-42.

105. Huang RY, et al. An EMT spectrum defines an anoikis-resistant and spheroidogenic intermediate mesenchymal state that is sensitive to ecadherin restoration by a src-kinase inhibitor, saracatinib (AZD0530). Cell Death Dis. 2013;4:e915.

106. Liao TT, Yang MH. Revisiting epithelial-mesenchymal transition in cancer metastasis: the connection between epithelial plasticity and stemness. Mol Oncol. 2017:11:792-804.

107. Jolly MK, Mani SA, Levine H. Hybrid epithelial/mesenchymal phenotype(s): the 'fittest' for metastasis? Biochim Biophys Acta Rev Cancer. 2018;1870:151-7.

108. Beerling $E$, et al. Plasticity between epithelial and mesenchymal states unlinks EMT from metastasis-enhancing stem cell capacity. Cell Rep. 2016;14:2281-8.

109. Nieto MA, Huang RY, Jackson RA, Thiery JP. EMT: 2016. Cell. 2016;166:21-45.

110. Chaffer CL, San Juan BP, Lim E, Weinberg RA. EMT, cell plasticity and metastasis. Cancer Metastasis Rev. 2016;35:645-54.

111. Aiello NM, et al. EMT subtype influences epithelial plasticity and mode of cell migration. Dev Cell. 2018;45:681-695.e4.

112. Brabletz T, Kalluri R, Nieto MA, Weinberg RA. EMT in cancer. Nat Rev Cancer. 2018:18:128-34

113. Campbell K. Contribution of epithelial-mesenchymal transitions to organogenesis and cancer metastasis. Curr Opin Cell Biol. 2018;55:30-5.

114. Chen Y, et al. Dual reporter genetic mouse models of pancreatic cancer identify an epithelial-to-mesenchymal transition-independent metastasis program. EMBO Mol Med. 2018;10:10.

115. Lianidou ES. Gene expression profiling and DNA methylation analyses of CTCs. Mol Oncol. 2016;10:431-42.

116. Hensler $\mathrm{M}$, et al. Gene expression profiling of circulating tumor cells and peripheral blood mononuclear cells from breast cancer patients. Oncoimmunology. 2015;5:e1102827.

117. Onstenk W, et al. Gene expression profiles of circulating tumor cells versus primary tumors in metastatic breast cancer. Cancer Lett. 2015;362:36-44.

118. Magbanua MJM, et al. Expanded genomic profiling of circulating tumor cells in metastatic breast cancer patients to assess biomarker status and biology over time (CALGB 40502 and CALGB 40503, Alliance). Clin Cancer Res. 2018;24:1486-99.

119. Lang JE, et al. RNA-Seq of circulating tumor cells in stage II-III breast cancer. Ann Surg Oncol. 2018;25:2261-70.

120. Barbazán J, et al. Molecular characterization of circulating tumor cells in human metastatic colorectal cancer. PLoS One. 2012;7:e40476.

121. Vishnoi M, et al. The isolation and characterization of CTC subsets related to breast cancer dormancy. Sci Rep. 2015;5:17533.

122. Kwan TT, et al. A digital RNA signature of circulating tumor cells predicting early therapeutic response in localized and metastatic breast cancer. Cancer Discov. 2018;8(10):1286-99.

123. Yeung $C$, et al. Estrogen, progesterone, and HER2/neu receptor discordance between primary and metastatic breast tumours-a review. Cancer Metastasis Rev. 2016;35:427-37.

\section{Publisher's Note}

Springer Nature remains neutral with regard to jurisdictional claims in published maps and institutional affiliations.

\section{Ready to submit your research? Choose BMC and benefit from:}

- fast, convenient online submission

- thorough peer review by experienced researchers in your field

- rapid publication on acceptance

- support for research data, including large and complex data types

- gold Open Access which fosters wider collaboration and increased citations

- maximum visibility for your research: over $100 \mathrm{M}$ website views per year

At BMC, research is always in progress.

Learn more biomedcentral.com/submissions 